\title{
The Impact of Visual Metaphor Complexity in Print Advertisement on the Viewer's Comprehension and Attitude
}

\author{
Wafa Chakroun \\ English Department, Higher Institute of Human Sciences in Medenine, Medenine, Tunisia \\ Email address: \\ wafa.chakroun@laposte.net \\ To cite this article: \\ Wafa Chakroun. The Impact of Visual Metaphor Complexity in Print Advertisement on the Viewer's Comprehension and Attitude. \\ Communication and Linguistics Studies. Vol. 6, No. 1, 2020, pp. 6-9. doi: 10.11648/j.cls.20200601.12
}

Received: September 17, 2019; Accepted: December 25, 2019; Published: January 17, 2020

\begin{abstract}
Visual rhetoric is considered a powerful tool of persuasion. It is widely used in political discourse, poetry and advertising language. This study tackles the topic of visual metaphor in print advertisements. It examines visual metaphor complexity on the viewer's comprehension and attitude. It uses Phillips and Mc Quarrie's classification of visual metaphor which offers an accurate classification of the different types of visual rhetoric. It distinguishes two dimensions, namely; visual structure and meaning operation. The former refers to the nature of the relation between the two pictures in comparison while visual structure refers to the way the relevant pictures are placed together. The combinations of the two dimensions result in nine types of visual metaphor which are: Juxtaposition/connection, juxtaposition/similarity, juxtaposition/opposition, fusion/connection, fusion/similarity, fusion/opposition, replacement/connection, replacement/similarity and replacement/opposition. The main findings show that complex and rich visual metaphors are more difficult to understand and are not positively perceived by the viewers. In fact, viewers of visual metaphor enjoy solving incongruity and are willing to devote extra efforts in understanding and processing visual metaphor. However, a complex and rich visual metaphor is not very appealing as their complexity will lead the viewers to opt out from enjoying and processing visual metaphor incongruity.
\end{abstract}

Keywords: Visual Metaphor, Visual Structure, Meaning Operation, Comprehension, Attitude

\section{Introduction}

The extensive use of visual metaphor in print advertisements led the topic of visual rhetoric a rich and valuable area of research for scholars and researchers. According to Mc Quarrie and Mick [2], visual rhetoric is "a rhetorical figure that occurs when an expression deviates from expectation, the expression is not rejected as nonsensical or faulty, the deviation occurs at the level of form rather than content, and the deviation conforms to a template that is invariant across a variety of contents and contexts (p. 425)". This study focuses on the classifications of visual metaphor according to their degree of complexity. The literature review revealed three main classifications, namely; Forceville's [3], typology, Philips and Mc Quarrie's [1] classification and Gkiouzepas and Hogg's [4], typology. This study uses Philips and Mc Quarrie's [1] classification because it offers a complete framework to the classification of visual metaphor complexity.

\section{Visual Metaphor in Philips and Mc Quarrie's (2004) Typology}

In their typology, Philips and Mc Quarrie's [1] classify visual metaphor into nine types based on their visual rather than verbal elements, and according to their level of complexity and ambiguity. In their classification, the aforementioned authors used two dimensions, namely; visual structure and meaning operation which are described in what follow.

\subsection{Visual Structure}

According to Lagerwerf et al. [5] visual structure refers to the manner the relevant pictorial elements are shown visually with an increasing degree of complexity. 
Henceforth, visual structure deals with the level of complexity and it includes three concepts; namely, juxtaposition, fusion, replacement and similarity Philips and Mc Quarrie's [1]. In Juxtaposition, the two objects are placed next to each other, while fusion involves fusing the two images together. The third dimension, replacement, one image replaces the other in such a way that the present image reminds of the absent image (ibid).

\subsection{Meaning Operation}

Phillips and Mc Quarrie [1] define meaning operation as "the nature of the relation between the two objects in comparison and to the target or focus of the cognitive processing required to understand the picture" (p. 116). They claim that the typology of meaning operation distinguishes three values: connection, similarity and comparison. Connection means that the two images are intended to be linked rather than compared. In similarity, the two elements are similar and the viewer is invited to compare the two images in order to detect one or more similarity. The third value, opposition, suggests that the two images are different in some way. More interestingly, the dimension of meaning operation has been associated with the concept of richness which is defined as "the degree and range of processing opportunity afforded by the various meaning operations" Philips and Mc Quarrie's [1]. The richness concept also refers to ambiguity. In fact, a metaphor is considered richer if there are more inferences that can be revealed and lead to multiple responses.

\section{The Impact of Visual Rhetoric on the Viewers' Comprehension}

According to Phillips and Mc Quarrie [1], juxtaposition and fusion are less complex to understand than replacement. Their typology assumes that as complexity increases, so does comprehension. Madupu et al. [6], however, show partial agreement to the aforementioned assumption as their study finds that fusion structure are more difficult to be understood than visual metaphors with juxtaposition or replacement. On the other hand, Gibbs [7], Sperber and Wilson [8] state that metaphor does not require extra effort to be understood. In the same context, Morgan and Richert's [9] state that abstract metaphors are found to be more difficult to be understood. Henceforth, comprehension decreases from juxtaposition to fusion and from fusion to replacement. Also, it has been found that too complex metaphors may not be understood than less complex metaphors as the comprehension of visual metaphors is systematically dependent with their degree of complexity (Forceville [3]). The aforementioned claims let advance the following hypothesis.

H1: An advertisement containing a complex visual structure and a rich meaning operation decreases the viewer's comprehension.

\section{The Impact of Visual Rhetoric on the Viewer's Attitude}

The effect of visual rhetoric complexity on the viewer's attitude has been subject of debate. Indeed researchers that have tackled this issue have come up with different findings. Their studies show that visual content in commercials increases the viewer's positive attitude towards the product just like verbal content (Rossiter and Perc [10]). Indeed, just like pleasurable language and music, non-literal language is thought to increase liking. In other words, successful incongruity resolution can lead to a positive effect or liking which is manifested in the processing of the commercial, brand awareness and persuasion (Meyers-Levy and Tybout [11]). Besides, it has been found that the presence of a rhetorical device increases appreciation and that this appreciation becomes stronger with the moderator effect of the consumer's involvement (Mzoughi [12]). However, a high level of complexity may have a negative effect on the appreciation as the comprehension of the commercial becomes more difficult. Indeed, Foreceville [3] show that the typology of visual metaphor offers a prediction that complex visual metaphor, which requires greater cognitive effort, will be better appreciated than less complex ones. Besides, there is no linear relationship between complexity and appreciation (Forceville [3]). A challenging cognitive effort used to interpret a visual metaphor may entail a risk in terms of the advertisement appreciation because appreciation follows a $\mathrm{U}$ curve. In other words, whether the message requires too much or too little cognitive effort, the appreciation decreases as the reader is not willing to interpret the metaphor (Forceville [3]). Therefore, the relation between perceived complexity and appreciation tends to be negative. The aforementioned claims led to the development of the following hypothesis.

H2: An advertisement containing a complex visual structure and a rich meaning operation engenders a negative attitude for the viewer.

\section{Methodology}

\subsection{Corpus}

The corpus was based on choosing print advertisements containing visual metaphor and following the nine types of visual structure in Phillips and Mc Quarrie's [1]typology. The selection criteria adopted Forceville's [3] approach which assumes that visual metaphor has two meanings: a literal primary meaning and a figurative secondary meaning. Therefore, the identification of the metaphor relied on the answer of the following three questions: (1) what are the two terms of the metaphor? (2) Which of the two terms is the literal meaning (A meaning) and which is the figurative meaning (B meaning)? What features are mapped from $\mathrm{B}$ to A (De la Rosa [13]). These questions have been used to analyze the selected print advertisements. 


\subsection{Procedure}

This study has two dependent variables, namely comprehension and attitude. Comprehension has been operationalized through six items using a seven-point semantic differential scale: 'Difficult to understand-Easy to understand', 'unintelligible-Intelligible', 'Unclear-Clear', 'Ambiguous-Certain'. The second variable, attitude, was measured using six items on a seven-point semantic differential scale: 'Unpleasant-Pleasant', 'Boring- Funny' 'Not entertaining -Entertaining', 'Ugly-Pretty', 'Dislik-Like', 'Not enjoyable-Enjoyable'. As far as the independent variable is concerned, this variable included nine visual combinations as described in Phillips and Mc Quarrie's [1] typology.

\subsection{Sampling and Data Collection}

Students of English represent the main target in this research. The selection followed a convenience sampling. A total of 170 questionnaires were distributed to the students of English at the faculty of Letters and Humanites of Sfax. However, a total of 158 questionnaires were retained because 12 questionnaires were rejected due to non-response.

\subsection{Data Analysis and Findings}

The first analytical tool being used in this study was a factor analysis for the dependent variables. The KMO and reliability coefficient for comprehension and attitude were satisfactory and equal to $0.867 / \alpha=0.940$ and $0.910 / 0.950$, respectively. A mean difference test (ANOVA) was used as a next step to test the null hypothesis that all the means between the categories of the independent variable, type of visual metaphor, are equal. In other words, the type of visual metaphor does not have an effect on the reader's comprehension and attitude. In what follows, the means difference and the Anova F-test are presented.

Table 1. Means difference for the variable Comprehension.

\begin{tabular}{llll}
\hline & Connection & \multicolumn{2}{l}{ Meaning operation } \\
\cline { 3 - 4 } & Juxtaposition & Similarity & Opposition \\
\hline \multirow{3}{*}{ Visual } & $\mathrm{M}=1.012$ & $\mathrm{M}=1.170$ & $\mathrm{M}=-1.141$ \\
structure & $\mathrm{M}=0.726$ & Fusion & Fusion \\
& Replacement & $\mathrm{M}=0.366$ & $\mathrm{M}=-1.132$ \\
& $\mathrm{M}=0.132$ & Replacement & Replacement \\
& & $\mathrm{M}=-0.132$ & $\mathrm{M}=1.036$ \\
\hline
\end{tabular}

Table 2. F-test for comprehension.

\begin{tabular}{llll}
\hline Variable & Mean square & F & sig \\
\hline Comprehension & 132.612 & 525.811 & .000 \\
\hline
\end{tabular}

Table 1 shows the means difference between the different types of visual metaphor. For the meaning operation of connection, the means between the different types of visual structure are different $\left(\mathrm{M}_{\mathrm{juxtaposition}}=1.012 ; \mathrm{M}_{\text {Fusion }}=0.726\right.$; $\mathrm{M}_{\text {Replacement }}=0.132$ ). Also, the meaning operation of similarity shows different means across the different types of visual structure $\left(\mathrm{M}_{\text {juxtaposition }}=1.170 ; \mathrm{M}_{\text {Fusion }}=0.366\right.$; Replacement $=$ -
0.132). Similarly, the means are different across the different groups of visual structure for the meaning operation of opposition $\quad\left(\mathrm{M}_{\text {juxtaposition }}=1.141 ; \quad \mathrm{M}_{\text {Fusion }}=-1.132\right.$; Replacement=1.036). Table 2 confirms a significant difference across the types of visual structure $(\mathrm{F}=525.811$; $\mathrm{p}=0.000<0.005$ ). Henceforth, the type of visual metaphor has a significant effect on the viewer's comprehension. H1 states that an advertisement containing a more complex visual structure decreases the viewer's comprehension. According to tables 1 and 2, H1 is accepted and a visual metaphor that has a meaning operation of similarity and visual structure of juxtaposition has the highest mean $(\mathrm{M}=1.170)$ and it is the easiest to be understood and comprehended by the viewers. However, a visual metaphor that is made up of opposition and juxtaposition is the most difficult to be understood by the viewers.

Table 3. Means difference for the variable attitude.

\begin{tabular}{llll}
\hline & \multirow{2}{*}{ Connection } & \multicolumn{2}{l}{ Meaning operation } \\
\cline { 3 - 4 } & Juxtaposition & Similarity & Similarity \\
\hline \multirow{3}{*}{ Visual } & $\mathrm{M}=0.924$ & $\mathrm{M}=1.191$ & $\mathrm{M}=1.191$ \\
structure & $\mathrm{M}=0.563$ & Fusion & Fusion \\
& Replacement & $\mathrm{M}=0.338$ & $\mathrm{M}=0.338$ \\
& $\mathrm{M}=0.204$ & Replacement & Replacement \\
& & $\mathrm{M}=-0.075$ & $\mathrm{M}=-0.075$ \\
\hline
\end{tabular}

Table 4. F-test for the variable attitude.

\begin{tabular}{llll}
\hline Variables & Mean square & F & sig \\
\hline Attitude & 119.854 & 368.040 & .000 \\
\hline
\end{tabular}

According to table 3 , the means across the different types of visual metaphors are different. For a meaning operation of connection the means are as follows: $\mathrm{M}_{\text {juxtaposition }}=0.924$; $\mathrm{M}_{\text {Fusion }}=0.563$; Replacement $=0.204$. Similarly, the means are different for similarity $\left(\mathrm{M}_{\text {juxtaposition }}=1.191 ; \mathrm{M}_{\text {Fusion }}=0.338\right.$; Replacement $=-0.075$ ). In addition, the meaning operation of opposition shows different means $\left(\mathrm{M}_{\text {juxtaposition }}=-1.101\right.$; $\mathrm{M}_{\text {Fusion }}=-1.045$; Replacement=--1.010). The significance of the means difference is presented in table 4 which shows that the $\mathrm{F}$ test is significant $(\mathrm{F}=368.040, \mathrm{p}=0.000<0.005)$. Therefore, $\mathrm{H} 2$ that states an advertisement containing a complex visual structure negatively impacts the viewer's attitude is accepted. Indeed the visual metaphor that is composed of a meaning operation of opposition and a visual structure of juxtaposition elicits more positive attitude on the viewer as it shows the highest mean $\mathrm{M}=1.191$, while the visual metaphor of Opposition/juxtaposition engenders less positive attitude among the viewers $(\mathrm{M}=-1.101)$.

\section{Discussion}

This piece of study used Phillips and Mc Quarrie's [1] typology to examine the effect of the types of visual metaphor on the viewer's comprehension and attitude. Choosing the aforementioned typology was not haphazard. Indeed, this typology offers the clearest and most accurate classification of the nine types of visual metaphor according 
to their visual structure complexity and meaning operation richness. This research attempted to test the impact of visual metaphor on the viewer's comprehension and attitude by using Anova test across the different groups of visual structure and meaning operation. Results show that viewers enjoy solving and understanding visual metaphor that is not so difficult neither so complicated. In other words, findings show that juxtaposition is the easiest and most appreciated visual structure to understand than fusion or replacement. As far as meaning operation is concerned, similarity is the most understood and liked when it comes to the type of meaning operation. Therefore, readers prefer to solve a print advertisement that places the two images next to each other (juxtaposition) and that the two pictures are similar so that the viewer can compare the two images and find one or more similarities. Henceforth, viewers enjoy solving incongruity when it is moderate, otherwise; they will just opt out from understanding and enjoying the commercial.

\section{Conclusion}

To sum up, this study offers a theoretical contribution that lies in its attempt to develop a clearer framework about visual metaphor in theory. It has also tried to understand the literature gap in terms of the effect of the type of visual metaphor on the viewer's comprehension and attitude and to help practitioners in the area of advertising have an idea about the impact of the type of visual metaphor on the viewer's comprehension and attitude. Indeed, using visual metaphor in advertisement is highly recommended as it is original and very appealing and has a persuasive effect on consumers. This use, however, should take into account that too much incongruity in visual metaphor will lead to negative outcomes. In fact, it is recommended for advertisers to use visual structure of juxtaposition and a meaning operation of similarity which are easier to understand and engenders more positive attitude than a meaning operation of connection or opposition. The most complex visual structure and richest meaning operation, namely replacement and opposition should be used with a verbal text or any other clue that helps the reader solve the incongruity. To conclude, this study does not escape from some limitations. First, this piece of study used different advertisements for the different types of visual metaphors. Such a use may have an effect on the viewers' responses. It will be interesting to focus in the future research on one advertisement which includes the same two pictures but placed differently according to the type of visual metaphor. It is also recommended to include moderator variables such as reader's involvement and motivation to be engaged in challenging activities.

\section{References}

[1] Philips, B. J. and Mc Quarrie, E. F. (2004). Beyond visual metaphor: A new typology of visual rhetoric in advertising. Marketing Theory, 4, 113-136.

[2] Mc Quarrie, E. and Mick, D. (1996). Figures of Rhetoric in Advertising Language. Journal of Consumer Research, 22, 424-437.

[3] Forceville, C., Le Pair, R., Van Mulken, M. (2010). The impact of perceived complexity, deviation and comprehension on the appreciation of visual metaphor in advertising across three European countries. Journal of Pragmatics, 42, 34183430 .

[4] Gkiouzepas, L. and M. K. Hogg (2011). Articulating a new framework for visual metaphors in advertising. A Structural, Conceptual, and Pragmatic Investigation, Journal of Advertising, 40, 103-120.

[5] Lagerwerf, L., Hooijdonk, C., \& Korenberg, A. (2012). Processing visual rhetoric in advertisements: Interpretations determined by verbal anchoring and visual structure. Journal of Pragmatics, 44, 1836-1852.

[6] Madupu, V., Sen, S. and Ranganathan, S. (2013). The impact of visual structure complexity on Ad liking, elaboration and comprehension. Marketing Management Journal, 23, 58-70.

[7] Gibbs, R. W. (1994). The poetics of mind: Figurative look on the bright side (consistent idiom) thought, language, and understanding. New York: Cambridge University Press.

[8] Sperber, D. and Wilson, D. (1986). Relevance: Communication and Cognition. Oxford: Basil Blackwell.

[9] Morgan, S. E. \& Reichert, T. (1999). The message is in the metaphor: assessing the comprehension of metaphors in advertisements. Journal of Advertising, 28, 1-12.

[10] Rossiter, J. R. and Percy, L. (1980). Attitude Change Through Visual imagery in advertising. Journal of Advertising, 9, 10.

[11] Meyers-Levy, J. and Tybout, A. M. (1989). Schema congruity as a basis for product evaluation. Journal of Consumer Research, 16, 39-54.

[12] Mzoughi, N., \& Abdelhak, S. (2011). The Effects of Rhetoric on Experiential Responses to Advertising. International Journal of Business and Commerce, 1, 36-50.

[13] De la Rosa, V. M. (2009). The Role of Pictorial Metaphor in Magazine Advertising. Revista Alicantina de Estudios Ingleses, 22, 167-180. 